\title{
D el elogio de la diferencia y la crítica de la desigualdad a la ética de la similitud
}

\author{
M aría Jesús Izquierdo \\ U niversitat Autònoma de Barcelona. D epartament de Sociologia \\ 08193 Bellaterra (Barcelona). Spain
}

Resumen

Este trabajo persigue presentar lo que se podría denominar crítica de segundo orden. Parte de algunos conceptos cuyo uso se ha generalizado en la sociología del género con el fin de mostrar que los mismos no sólo son instrumentos para cuestionar la naturaleza patriarcal del orden social, sino también su síntoma. La autora sostiene que algunos aspectos de la conceptualización relativa al sexismo y a la desigualdad social de las mujeres, son la manifestación de la identidad de género bajo condiciones patriarcales. En particular la tendencia a consignar la conveniencia de hacer visible el trabajo de las mujeres, la necesidad de evaluar el trabajo doméstico, y la utilización del término reproducción, cuando se aplica al trabajo doméstico de las amas de casa.

Palabras clave: sociología del género, trabajo doméstico, patriarcado, identidad de género.

\section{Abstract}

This work aims to present what could be called a second order critics. It takes a number of concepts which use is generalized in the sociology of gender, in order to show them not only as the instruments to question the patriarchal nature of social order, but also as its symptom. The author holds thad some aspects of the conceptualization made of sexism and women's social inequality are the manifestation of gender identity under patriarchal conditions. Particularly the tendency to consign the convenience of making visible the work of women, the need for and evaluation of domestic work, and the use of the term reproduction, when apllied to the domestic work of housewives.

Key words: gender sociology, domestic work, patriarchy, gender identity.

Cuando se reflexiona sobre el proceso y los resultados de las actividades de investigación, conviene abordar tres dimensiones, que no siempre se ponen en evidencia, aún cuando se hallan íntimamente relacionadas:

1. Las motivaciones que conducen a una persona a implicarse en actividades de este tipo y a elegir el objeto de estudio.

2. Las condiciones en las que se desarrolla su actividad. Recursos humanos, fuentes de financiación, recursos materiales, objetivos profesionales, destino de los resultados.

3. Elección de marco teórico, desarrollo y uso de conceptos, método, técnicas. 
En las próximas páginas quisiera referirme a estas dimensiones del problema en relación con el estudio de la construcción de la subjetividad, porque tal vez sea el objeto con el que principalmente se me identifica, cosa que no deja de ser sorprendente, ya que el grueso de mi producción tiene que ver con el trabajo y la familia. Al mismo tiempo, no puede olvidarse que es un sujeto quien investiga, expresando su modo de ser en su modo de hacer, hecho al que generalmente se presta poca atención. Q uien reconoce la existencia de un sujeto investigador tras toda investigación, suele, al mismo tiempo, borrar su propia subjetividad cuando presenta los resultados de su trabajo. Empezaré presentando las condiciones y deseos que orientaron mis actividades profesionales hacia la docencia y la investigación, con el ánimo de facilitar claves de lectura para mi trabajo. M e parece deshonesto no hacerlo, dado que el grueso de estas páginas está dedicado a hacer visible la presencia del sujeto investigador y su contexto en el producto que desarrolla.

\section{El sujeto, su contexto y su modo de investigar}

C reo que cuando nos referimos a cualquier acción humana las preguntas primeras son: quién, por qué, para qué y en qué circunstancias hace lo que hace. Si se prefiere plantear de un modo más simple: qué expresamos a través de lo que hacemos. Tomaré como punto de partida 1976 - si la memoria no me engaña- , en el local que el párroco de una iglesia cedía a la Coordinadora Feminista para que celebrara sus reuniones, cosa que desde luego no nosimpedía denunciar a la I gl esia por su complicidad en el mantenimiento de todo género de desigual dades, particularmente la de las mujeres. Asistía a aquella reunión en calidad de representante de la Vocalía de M ujeres del Valle de $\mathrm{H}$ ebrón y de la Asociación de M ujeres de ese mismo barrio ${ }^{1}$. En las reuniones de la Coordinadora Feminista nos encontrábamos obreras, amas de casa, universitarias, lesbianas, radicales, moderadas, militantes de partidos políticos de izquierdas, militantes de movimientos sociales, partidarias de la segregación política respecto de los hombres, y las que consideraban posible y necesaria la colaboración con ellos. M ujeres todas ellas que vivían su compromiso social y político con vehemencia. Con tal diversidad no hace falta decir que las discusiones eran apasionadas, ya que las posiciones políticas abarcaban un abanico muy amplio. Teníamos objetivos comunes y teníamos también discrepancias irreductibles.

1. Se trataba de las mismas mujeres con distintos sombreros. G eneral mente funcionábamos bajo el paraguas de la Asociación de Vecinos, como Vocalía de M ujeres, salvo que nuestros compañeros objetaran respecto de al guna propuesta, por considerarla demasiado radical 0 comprometida, en cuyo caso actuábamos bajo el paraguas de la Asociación de M ujeres. Las tensiones entre los objetivos del movimiento ciudadano y el movimiento feminista las resolvíamos diferenciando nuestras actuaciones. $H$ ay que señalar que respecto de nuestros planteamientos políticos no éramos un colectivo homogéneo. 
Creo recordar que en aquel momento lo que más me preocupaba era cómo ganarme la vida de un modo estable y suficiente, cómo conseguir que el trabajo asalariado no me impidiera el cuidado de mi hijo - tenía un año y medioy qué contribución podía hacer a cambiar el mundo - porque creía que alguna cosa podía y debía hacer - . Lo que más me movilizaba era la desigualdad social de las mujeres, y lo más urgente era acabar con el franquismo.

Algunos de los impactos intelectuales y emocionales más intensos que he experimentado en mi vida se produjeron en esas reuniones de la Coordinadora Feminista. Recuerdo que me acercaba a las mujeres entre alucinada y deslumbrada, ansiando saber lo que ellas sabían. Les pedía que me dijeran cómo lo habían aprendido, dónde estaba escrito, porque quería participar de ese conocimiento. Las compañeras de la Coordinadora Feminista pertenecientes a grupos de afinidad ideológica como La M ar o el Colectivo Feminista me quitaban el aliento con sus análisis, sobre todo por su desobediencia sacrílega hacia el pensamiento de la izquierda desde la izquierda misma. Ellas me dieron a conocer dos textos que son de los que me han causado mayor impacto, aunque no hayan sido los más decisivos para mi formación intelectual: «EI principal enemigo» de C hristine $D$ el phy y La dialéctica del sexo de Shulamith Firestone. En aquel momento ya conocía El segundo sexo de Simone de Beauvoir, y La mística de la femini dad de Betty Friedan, libros que viví como primera legitimación de mi queja por el sufrimiento que me causaba el sexismo. N o necesitaba apelar a la solidaridad para comprometerme políticamente, ya que se hablaba de los problemas que yo tenía, no de los que tenían los demás. Se trataba de defender mis propios intereses en aquello que más me movilizaba, la desigualdad social a la que me sentía sometida por el hecho de ser mujer.

D e lo dicho es cabal desprender que asocio mis ambiciones intelectuales a la militancia política feminista, y no a la práctica profesional. Eso tiene varias consecuencias sobre qué y cómo investigar y sobre la propia trayectoria profesional.

M i formación de base es la economía, y mis primeras actividades docentes se desarrollaron en el campo de esta disciplina. La economía me continúa gustando como me gustó en el momento en el que elegí estudios. Sin embargo, desemboqué en la sociología porque constataba las dificultades de encaminar mis intereses intelectuales hacia la situación social de las mujeres partiendo de esa disciplina, por el rechazo con el que era recibido el feminismo en los ámbitos académicos, y por el hecho de que el ámbito de la sociología era más amigable, no olvidaré el respaldo de mis compañeros de departamento cuando leí la tesis doctoral en la Facultad de Ciencias E conómicas de esta U niversidad. $H$ ay que añadir que la economía no meinteresaba en sí misma, sino por la importancia que para mí siempre ha tenido la dimensión económica en nuestras vidas, mi fantasía era formarme en planificación socioeconómica. En cuanto a mi incorporación a la universidad en calidad de docente, tiene mucho que ver con el intento de compatibilizar el trabajo remunerado con el cuidado de mi hijo, que en ese momento era muy 
pequeño. N o obstante, la vinculación con la sociología está relacionada, sobre todo, con mi compromiso político.

Insisto en estas cuestiones porque ayudan a comprender el hecho de que nunca haya experimentado una gran pasión por referir mi identidad intelectual a alguna disciplina particular, más bien me dejan fría los esfuerzos encaminados a armar las fronteras entre las distintas disciplinas, porque sospecho que tie nen más que ver con el poder que con el saber, con la carrera académica que con el compromiso social. Lo dicho tiene consecuencias en la manera de trabajar que se expondrán a continuación.

\section{Las condiciones de investigación}

El punto de arranque de mis actividades investigadoras es la participación en jornadas de estudio y encuentros feministas. En ocasión de las II Jornades Cata lanes de la D ona de 1982, presento por primera vez la diferenciación conceptual entre sexo y género con la ponencia «Breve introducción al estudio de hombres, mujeres y otros géneros y sexos», que habría de dar lugar a un libro: Las, Ios, les, (lis, lus) 2, que a su vez se desarrollaría en mi tesis doctoral: El pro blema de la clasificación en las Ciencias Sociales: El caso de la clasificación mujer/varón.

El trabajo de investigación ha tenido dos niveles, el teórico/conceptual y el empírico. El de carácter teórico/conceptual, lo he realizado sin apoyarme en financiación. También he participado en investigaciones fundamentalmente empíricas, encuadradas en convenios, con las que he podido mejorar mis ingresos. Recientemente me he planteado no obtener ingresos con la investigación, ya que es un camino que puede conducir a que las actividades docentes ocupen un lugar secundario. En este momento, los ingresos de profesora me permiten cubrir las necesidades materiales con un grado de confort suficiente, cosa que me coloca en una posición privilegiada para orientar las actividades investigadoras.

En mi situación actual parto de lo que me despierta interés político y/o intelectual, y a la vez procuro interesarme por proyectos que no requieran financiación. Esto último por lo ya mencionado, y porque el tipo de trabajos que suelen obtener financiación se acercan mucho a lo que se podría definir como informe profesional, más que como investigación propiamente dicha, 0 bien llevan a acomodar los propios intereses investigadores a programas gene rales sobre cuyo diseño no se tiene intervención. Adicionalmente, se puede caer en una competencia desleal como las personas en cuya formación participo. Asimismo, la creación de grupos de investigación que den lugar a trabajo remunerado fuerza a garantizar una cierta continuidad laboral de las personas que participan en los mismos, así como unas condiciones de contratación acepta

2. Las, los, les, (lis, lus). El sistema sexo/género y la mujer como suj eto de transormación social, Barcelona, laSal Ed. de les dones, 1983. 
bles, cuestiones éstas que pueden conducir a buscar fuentes de financiación, no tanto para poner proyectos en práctica como para sostener los equipos de trabajo. En ese punto se empieza a hacer difícil diferenciar un equipo de investigación de una empresa de servicios.

No puede olvidarse, sin embargo, que quien factura eingresa es la universidad, y que la vía de convenios constituye una fuente de ingresos adicionales nada despreciable. Es comprensible que, dadas las dificultades de financiación por las que pasa la universidad, la prestación de servicios a empresas privadas o entes públicos, no sólo sea mirada con buenos ojos, sino incluso estimulada por las autoridades universitarias.

Antelas consideraciones previas, me he planteado cómo satisfacer tres objetivos fundamentales: preservar la independencia como investigadora, no separar las actividades docentes de las investigadoras y no crear compromisos laborales con los equipos que me lleven a buscar fuentes de financiación para conservarlos. Recientemente he formado un grupo de estudios: Grup d'Estudis: Sentiments, Emocions i Societat (GESES), abierto a la participación de estudiantes de segundo y tercer ciclo. D ado que no hay un elemento exterior que facilite su estructuración y continuidad, nos hemos dotado de unas reglas de juego mínimas, para la continuidad del grupo y la permanencia de sus participantes en el mismo. La primera es que nos planteamos proyectos de investigación realizables sin necesidad de financiación. U na vez establecido el calendario de reuniones de trabajo, y las tareas que asume cada participante, se adquiere el compromiso de no faltar a las reuniones y no acudir sin haber realizado la tarea de la que dada cual se hace responsable. Asociamos a esas reglas la continuidad del grupo o de las participantes en el grupo. En el trabajo se alterna la formación con la investigación, y se fija al inicio de cada período un objetivo que permita materializar los trabajos del grupo. En el período ante rior el objetivo fue escribir dos artículos, en el próximo nos proponemos escribir un libro.

Este método de trabajo ya tenía un rodaje previo en una investigación anterior que condujo a la publicación de un libro, con el que se culminaron dos años de trabajo y algunos más de seminario de lectura, se trata de Aguantando el tipo ${ }^{3}$.

\section{El método y las técnicas}

Tiendo a considerar los aspectos estructural es e históricos de la situación social de las mujeres. Ello ha supuesto plantear el estudio de la situación psicosocial de las mujeres refiriéndola a la de los hombres. Se trata de relaciones y determinaciones mutuas de la posición «mujer» y la posición «hombre»; de la identidad «mujer» y la identidad «hombre». Junto a la perspectiva estructural, tiendo

3. Aguantando el tipo. D esigualdad social y discriminación salarial, Barcelona, D iputación, 1998.

Trabajo realizado con Clara Llorens, Enrico M ora y Esther Sánchez. 
a considerar la dimensión histórica en el paso de las sociedades feudales y el mercantilismo simple a las sociedades capitalistas. Por tanto, podríamos decir que creo moverme en el ámbito del método histórico/comparativo - ve a saber si sigo la tradición de Comte- o más bien el materialista histórico - siguiendo la tradición marxista- . Tal como entiendo el materialismo histórico, se trata de abordar el conocimiento sin separar ni tampoco confundir el saber, el querer y el poder, y sin plegarse a la parcelación disciplinaria. Todo lo que ocurre sucede porque se dan unas condiciones materiales que lo hacen posible, las cuales inciden, no solo en los acontecimientos, sino también en las ideas que se tiene sobre los mismos, y en su visibilidad o invisibilidad a ojos de los participantes. Adicionalmente, me propongo presentar las relaciones sociales y el cambio social en sus contradicciones, creo estar fuera de la órbita de influencia del positivismo. D igamos que me siento cómoda con el conocimiento crítico.

H asta ahora no he hecho una reflexión sistemática sobre la dimensión técnica del trabajo teórico, ni tan sólo me atrevo a hacer una primera aproxima ción al particular. Por ello me centraré en las técnicas referidas a la investigación empírica, intentando al mismo tiempo establecer una separación analítica entre lo teórico y lo empírico. Creo que procede comenzar señalando el forcejeo constante entre la «recogida» y la «construcción» de los datos. $D$ ado que he empezado esta ponencia señalando mi compromiso político, al que no renuncio, se explica que no me plantee problemas sociológicos, sino problemas socia les - o sea, todo lo contrario de lo que se propone desde la sociología- y eso en su doble vertiente: la identificación o visibilización, y la construcción. Sin embargo, a la que entramos en el trabajo, no solo de conocimiento, sino también de construcción de realidad, el problema social adquiere, junto a su dimensión práctica, una dimensión intelectual, por lo que al plantearme problemas sociales surgen problemas sociológicos.

Por lo general, he experimentado la sensación de estar violentando a las personas objeto de investigación, sensación que he podido situar tomando como referencia los trabajos de J esús I báñez, el cual presta atención a la dimensión del poder en el trabajo de investigación. La violencia tiene distinto carácter con cada una de las técnicas: en el caso de la entrevista estructurada con preguntas cerradas, una se siente como el vendedor de zapatos que está obsesionado con colocar un par al cliente, y se empeña en que los zapatos son cómodos, que en todo caso el problema es del pie. La tentación es obvia, recortar todo lo que se sale del zapato llevándose por delante los juanetes... y también los dedos, confundiendo, a menudo, qué son juanetes y qué dedos. He podido constatar esa tensión cada vez que he hecho una entrevista, y la he sentido yo misma cuando he intentado contestar a un cuestionario estructurado. Creo que la tensión procede de no querer mostrarse ni ser visto o vista del modo en que el cuestionario busca presentarte.

En cuanto a las entrevistas en profundidad, cuando las hago siento como si estuviera violando la intimidad, porque las cosas que de verdad merece la pena saber no se cuentan en una entrevista, y si quien entrevista las desea cono- 
cer está necesariamente viol entando al entrevistado o a la entrevistada. Cómo comprender mejor a la gente sin violentarla. Q ué se le puede pedir que quiera hacer, que disfrute haciéndolo. El trabajo de investigación que estamos desarrollando en la actualidad responde a esa inquietud. Tomamos los chistes como indicio de las relaciones entre la estructura psíquica y la estructura social, y la gente nos los da de buen grado.

\section{El elogio de la diferencia y la crítica de la desigualdad}

D e entre los caminos posibles para intervenir en una mesa cuyo título gené rico es $L$ a construcción de la subjetividad, he optado por hacer una reflexión doble: sobre la presencia del sujeto investigador en el discurso sobre la desigualdad social de las mujeres, y sobre las manifestaciones de la dimensión psíquica del patriarcado. Teniendo en cuenta que no puedo dar por supuestos los conceptos teóricos que utilizaré en la interpretación de los discursos, abriré este apartado con una breve reflexión sobre la dimensión psíquica del sujeto, tomando como punto de referencia el trabajo de Freud.

\section{La dimensión psíquica del sujeto}

Para interpretar los discursos y las acciones del sujeto, hay que revisar el proceso de construcción de la subjetividad y los mecanismos psíquicos que se desencadenan en un ser que se construye socialmente. En el proceso de maduración, que está relacionado con el reconocimiento de la existencia de una realidad exterior, distinta de una o uno mismo, la diferenciación se construye, en un primer momento, mediante la proyección de todo lo «malo»-que se refiere al estar mal- y la introyección de todo lo «bueno»- que remite al estar bien- . Cualquier cosa, actividad o cualidad que contribuya de un modo mediato o inmediato al bienestar se toma como «yo», y concibe todo aquello que se relaciona con el malestar como «no yo»4. U na manifestación de la madurez emocional es que el sujeto supere esa separación maniquea «yo»/ «real idad exterior», reconociendo como propias al gunas de las cual idades, acciones, o producciones que le generan malestar, superando su tendencia a rechazarlas, a constituir la «realidad exterior» mediante la proyección imaginaria de las mismas. Esta manifestación de madurez acompañada del reconocimiento de que al gunas de aquellas fuentes de bienestar que tomaba como si fueran parte de su ser, en virtud del mecanismo de la introyección, son ajenas, son «realidad exterior». La madurez lleva a la superación del maniqueísmo, a la aceptación de que una o uno mismo tiene cosas malas, hace cosas que le causan daño, y no es «malo» 0 amenazador to do lo que

4. El conocido mecanismo de la socialización de las pérdidas y la privatización de las ganancias, al que tan acostumbrados nos tienen los empresarios, recuerda sospechosamente el mecanismo al que nos referimos. 
viene del exterior, sino que, por el contrario, buena parte de nuestros momentos de bienestar y felicidad proceden de nuestra apertura al mundo. C abe decir que el proceso de maduración no significa que la persona haya vencido 0 anulado sus partes infantiles, sino que es capaz de hacerse cargo de ellas, dándose cuenta de cómo operan esos mecanismos de construcción de realidad, y por ello pudiendo contenerlos.

Pueden captarse abundantes manifestaciones de una construcción inconsistente de realidad exterior y, como me propongo mostrar más adelante, son particularmente frecuentes en los discursos sobre las mujeres. Es frecuente ver que los mismos refuerzan o construyen un ideal narcisista del «yo», en lugar de presentarlo con sus faltas y daños. Seguramente por eso suelen gozar de muy buena aceptación entre las propias mujeres. Cómo se explicaría, en cambio, que los hombres acepten este tipo de discursos, qué trampa emocional encierran para ellos. ¿Es demasiado temerario afirmar que tal vez en ellos anida el anhelo de esa madre omnipotente imaginaria que se resisten a abandonar? Esa madre que produce la vida humana ella sola, esa madre que el niño fantasea sin pareja porque no quiere crecer y separarse de ella.

Tomo las dificultades en el proceso de maduración como características estructurales del orden patriarcal moderno. La estructura psíquica la refiero en las dos dimensiones básicas de la acción ${ }^{5}$ : el deseo y el modo de actuación a través del cual se busca su satisfacción. Si hablo de estructura psíquica propia del patriarcado es porque considero que bajo ciertas circunstancias se debilita la dimensión del sujeto que remite a la posibilidad de autodeterminación, y debilita también la capacidad de reflexión sobre el grado limitado en que podemos al canzar la autonomía. H ay que añadir que se produce una confusión entre autonomía y omnipotencia. Las conductas seacercan a estereotipos asociados a rasgos de la estructura social, siendo productos de la misma y facilitadores de su reproducción. Y esto no solo vale para los colectivos oprimidos, sino que también es aplicablea los opresores. Cada una y cada uno es un producto patriarcal a su manera.

En lo que tiene de patriarcal la estructura psíquica de las mujeres, consiste en tomar como deseo el de ser deseada. Ese deseo se traduce en la necesidad de aprobación: «iM e quieres, Pepe?, jsoy tuyal». Su modo de acción es la «actividad de la pasividad», conseguir que sea el otro el que haga lo que una desea. C onsiste en conseguir que los demás encaminen su actividad a satisfacer los deseos que una tiene, sin que hayan sido expresados en forma de demanda. Ésta, al no ser respondida, puesto que se desconoce, emerge directamente en forma de queja y el otro se encuentra en deuda permanente. Ese modo de hacer y desear «femenino» late en las quejas de las mujeres, y tal vez permita entender, aunque sólo sea en parte, que las estudiantes aprueben más que los estudiantes, indicio de que saben hacer aquello que desean, ser aprobadas. El

5. Y a su vez me refiero a la acción porque estoy interesada en el ser humano como construcción, como proceso, no como punto de partida o como resultado. 
deseo profundo es ser objeto de deseo, pero no indiscriminadamente, sino «de una cierta manera» jamás expresada abiertamente - a pesar de que no haya sido expresado, precisamente porque no lo ha sido- , lo que puede conducir a que la mujer adquiera la apariencia de «objeto/cosa»6, por no manifestarse como sujeto deseante. Se trata de una estructura plagada de contradicciones, pues si de un lado todo depende de los demás, son ellos los que tienen que realizar los propios deseos, del otro, y en tanto se busca realizar los deseos como resultado de la manipulación de los deseos de los otros, se adquiere la ilusión de que se dominan sus voluntades. Esa actitud manipuladora conduce a que los fracasos se vivan con un intenso sentimiento de culpa, que conduce a actos autodestructivos. Se establece una asociación entre conservar la vida y ser amada, y se supone que ser amada sólo depende de una misma, como si fué ramos las mujeres las que producimos amor, negando que los hombres sean capaces de experimentarlo por sí mismos, sino como producto de nuestra voluntad y maniobras. En el fondo, tras esa sobrecogedora precariedad hay un fuerte sentimiento de omnipotencia, al no ser capaz de reconocer que buena parte de las cosas que le pasan están fuera de su control, y al mismo tiempo sentirse responsable de todas ellas.

En lo que tiene de patriarcal la estructura psíquica de los hombres, es bastante menos compleja que la de las mujeres. Los hombres experimentan el deseo en forma de necesidad de posesión del objeto de deseo, la mujer: «iTe quiero, Pepa, eres mía!». La mujer pregunta, el hombre afirma. La mujer desea que el hombre haga o le dé cosas, el hombre desea que la mujer se entregue, se deje hacer. En cuanto a la acción, en el caso del hombre, se trata de la «pasividad de la actividad»: «N o sé qué es lo que quiere, no sé qué demonios tengo que hacer para contentarla». Está dispuesto a dar lo que la mujer le pida - salvo entregarse a sí mismo, porque «no soy tuyo, sino que eres mía»- , ya que ella sólo se entregará si satisface sus demandas. Sin embargo, se lamenta de no entender cuál es la demanda incumplida, porque seduele de la falta de entrega, sin entender que el atractivo de esa promesa es precisamente que no se cumpla.

W eber expresaba con una belleza que raya en lo sublime: «El estuche ha quedado vacío de espíritu, quién sabe si definitivamente. En todo caso, el capitalismo victorioso no necesita ya de este apoyo religioso, puesto que descansa en fundamentos mecánicos». Y esto lo decía, seguramente porque intentaba comprender el sentido de las acciones de la clase dominante en tanto que clase dominante sin tener en cuenta las determinaciones de género. Pero si las tomamos en consideración, el estuche continúa lleno, aunque no sabemos por cuanto tiempo, sobre todo en los colectivos sociales más desfavore cidos económicamente, entre los cuales la división sexual del trabajo es más

6. Esta diferencia entre objeto/cosa y objeto/persona ha sido una palanca muy importante para enten der la dimensión psíquica de las relaciones de género. La idea la he tomado de Gayle RUBIN, «T he trafic of women: notes on the political economy of sex», en REITER (ed.), Toward an anthropology of women. N ueva York: M onthly Review Press, 1978. 
profunda y rígida. Para esos colectivos el estuche está lleno con la promesa de entrega de las mujeres a los hombres, promesa que dota de sentido las penalidades y humillaciones de las relaciones salariales, cuando uno, lo único que tiene para vender es su propia capacidad productiva como medio para lograr que la promesa por fin se cumpla. Lo único que puede llegar a poseer, no es la salvación, sino la mujer y los hijos. ¿N os sorprende, en esas condiciones, que la mate porque es suya, que la mate porque es la única manera de mostrar y mostrarse que es suya, que se sienta a su lado después de haberla matado?

\section{La expresión de la subjetividad en la investigación}

Ya me he referido más arriba a la importancia que atribuyo a las condiciones material es de existencia. Éstas se encuentran relacionadas con el sujeto en dos sentidos: lo construyen en tanto le marcan límites y en tanto los vence. Entiendo que el sujeto es y se hace en relación, con otros sujetos y con el entorno físico, siendo activo y pasivo a la vez, lo que es como decir que nuestro entorno y nuestras relaciones son sólo en parte una consecuencia buscada de nuestras acciones. También son lo que se encuentra sin haberlo buscado, de lo cual rechazamos al menos una parte. Somos autores de nuestras vidas en condiciones que no hemos el egido, y nuestra obra nos produce cierta sensación de extrañamiento. Podemos atribuir esa sensación a dos fuentes. Por una parte, es muy limitado el grado de elección de las condiciones y materiales con los que hacemos de nosotros lo que somos. En segundo lugar, y tal vez más importante, el producto imaginario nunca coincide con el real. Este segundo rasgo genera una dinámica, tan importante, que el proceso acaba siendo más importante que el resultado.

Estos son aspectos que deben situarse fuera del marco teórico, haciéndolo posible y condicionándolo. D e ahí surge la importancia que he atribuido a los conceptos «trabajo» y «división sexual del trabajo«. La preocupación política - la desigualdad social de las mujeres- es el motor de la actividad investigadora, pero esa desigualdad se conceptualiza a partir de la noción de trabajo y división sexual del trabajo. He abordado la división sexual del trabajo desde un punto de vista estructural: considerando que la misma genera formas de relación entre las mujeres y los hombres que condicionan el resto de sus vidas. E se tipo de visión favorece que se caiga en aproximaciones organicistas al contemplar las relaciones hombre/mujer como complementarias, y suponiendo que el conjunto es superior y distinto de la suma de sus partes. D os medias naranjas son menos que una naranja, porque ser media naranja no es otra cosa que la posibilidad de participar en la construcción de una naranja. Ser media naranja es, en definitiva, el «no ser» de la naranja, y la naranja el «no ser» de un ser humano individuado.

D e aquí podría derivarse que en mis aproximaciones supongo que la posición de las mujeres y los hombres en la familia condicionan su posición en otras esferas de la vida, o puesto en otras palabras: que el patriarcado condi- 
ciona el capitalismo. Es así pero con muchos matices. Entiendo que desde el punto de vista del desarrollo del sujeto, la constatación de las diferencias anatómicas entre los sexos se significa en forma de relaciones de poder y dependencia entre los hombres y las mujeres, y que en ello juegan un papel estructurante las relaciones familiares. Sin embargo, el marco en el que se constituyen las familias es el de la división social del trabajo, la primera entre poseedores de los medios de producción y poseedores de la fuerza de trabajo, y la organización de la producción que le es afín, fundamentada en la especializa ción funcional, en la división técnica del trabajo. La familia es fabricada socialmente y la familia fabrica las subjetividades que requieren confirmación fuera de las cuatro paredes del hogar.

¿En qué consisten los trabajos de las mujeres y los de los hombres? A lo largo del tiempo creo haber ido modificando la respuesta a esta pregunta. En «Feminismo no es sexismo» , - donde también Ilamo «trabajo doméstico» al «trabajo no asalariado»-8, me refiero a ambos tipos de trabajo como: «traba jo en dos esferas de la producción, la esfera de la producción de valores de uso y la de val ores de cambio», p. 83. Por tanto, considero implícitamente que el trabajo no asalariado de las mujeres es un trabajo productivo, y que la dife rencia entre el uno - remunerado- y el otro - no remunerado- radica en el hecho de que el primero tiene valor de cambio y el segundo de uso. Releído hoy lo que escribí entonces, me sugiere que el primero tiene un valor genérico «trabajo humano abstracto» y es un medio, el producto del trabajo se realiza en la enajenación, al desposeerse del mismo, en la venta. El segundo tiene un valor específico, es fin, el producto se realiza en su uso, en la incorporación, no en la enajenación. N os falta ver si es cierto que se trata de una producción de valores de uso, o si más bien en la parte de los productos usada 0 consumida por quien no lo realiza contiene, además de valor de uso, valor de cambio. Esta precisión reviste una importancia considerable, dado que el núcleo de la crítica a la realización de trabajo doméstico por parte de las mujeres se refiereal hecho de que se trata de un trabajo no pagado9. El camino que acabo de señalar nos conduciría a revisar el concepto de «valor de cambio», por su aplicación restringida a las llamadas actividades productivas.

¿Q ué tiene esto que ver con la construcción de la subjetividad? Si una mujer, cuando realiza las tareas de la casa, si ente que trabaja a cambio de nada, o trabaja como un fin en sí mismo, puede estar expresando a través de esta vivencia que no necesita nada de los demás y que en cambio los demás necesitan

7. «Feminismo no es sexismo. Algunas consideraciones sobre el trabajo asalariado y el trabajo no asalariado», M ientras tanto, nำ 7, 1981.

8. Cuando me pregunto por qué demonios le llamaba «trabajo no asalariado» al trabajo delas mujeres, lo que equivale a tomar como positividad el trabajo remunerado, caigo en la cuenta de que en aquel momento estaba muy preocupada con mi estabilidad profesional y tenía un nivel de ingresos muy bajo.

9. No ignoro que otra crítica, de la que participo, se refiere a la propia división sexual del trabajo. 
de ella. Cuando los demás se refieren a ella como alguien que realiza un trabajo gratuito, se produce la paradoja de que en la afirmación de su sometimiento se produce la afirmación de su omnipotencia, ya que se ignora que es un «ser-en-relación» al ignorarse el papel activo-productor del otro término, el marido, los hijos, o los padres viejos. Podríamos añadir otro interrogante: ¿qué se proyecta en estos discursos de la subjetividad de la investigadora? M e pregunto si no son una manifestación de sus fantasías omnipotentes.

Volviendo al artículo en cuestión ${ }^{10}$, señalaba que el trabajo de las amas de casa no es ni remunerado ni gratuito, puesto que el ama de casa recibe los medios que hacen posible su subsistencia. El trabajo remunerado se produce en condiciones que generan la alienación del trabajador. El trabajo de las amas de casa no produce su alienación como trabajadoras, sino como personas. Pude constatar esa cualidad particular del trabajo doméstico en una investigación sobre el uso del tiempolla pesar de las muchas limitaciones de la información obtenida a través de una encuesta con preguntas cerradas en abanico, donde la información tiene más de «dar forma a» que de «adquirir conocimiento de» la situación 12. T omando todas las preguntas que se referían al uso del tiempo y relacionándolas con la situación laboral y familiar, se evidenciaba que en algunos aspectos, como por ejemplo la percepción del tiempo disponible, las respuestas de las amas de casa eran muy similares a las de los profesionales denivel alto, y distintas a su vez de las dadas por los trabajadores y trabajadoras de otros niveles socioeconómicos. La percepción de las amas de casa y de los profesionales coinci día en que en ambos casos se manifestaba la ausencia de tiempo libre. Sin embargo, al computar el número de horas que decían dedicar a su actividad, se constataba que no era superior al de otros colectivos que no manifestaban falta de tiempo libre. En aquel momento entendí que esta paradoja significaba el hecho de que el tiempo de los profesionales de alto nivel y de las

10. En su origen se encuentra una ponencia presentada en las I Jornadas de M ujeres Indepen dientes cel ebradas en Barcelona. M ediante la denominadón «M ujeres I ndependientes», se señalaba que el compromiso con el movimiento feminista como «militancia única», posición que se contraponía a la de «doble militancia», para referirse a aquellas mujeres que además de pertenecer al movimiento feminista militaban en al gún partido político, de izquierdas, naturalmente. El debate entre las unas y las otras halla fiel reflejo en una canción: «cómo se pueden tener dos amores a la vez... y no estar loca. Aquí va mi explicación, pues me llaman sin saber, Corazón Loco.» M onogamia o poligamia era el debate, las «doble militantes» insistían en que su primer amor era el feminismo, y que su presencia en los partidos de izquierda era para extender la lucha feminista en su seno, las «independientess insistían en que tarde o temprano se produce la contradicción entre una y otra militancia.

11. La desigualdad de las mujeres en el uso del tiempo. Estudio realizado con la colaboración de O Iga del Río y Agustín Rodríguez y financiado por el Instituto de la M ujer, que lo publicó en 1988. Se tomaron como base, para la realización del mismo, los datos de la Enques ta M etropolitana 1986. Condicions de vida i hàbits de la població del'Á rea M etropolitana de Barcelona, de la cual fui codirectora junto con Faustino M iguélez y M arina Subirats.

12. En el sentido en que lo plantea Jesús I báñez cuando se refiere a las características de esta técnica de investigación. 
amas de casa tiene una calidad común, es autónomo, en ambos casos se pueden tomar decisiones sobre su uso, y por ello no es posible diferenciar la parte del tiempo quees «atado», heterónomo, y la que es «ibre», de uso autónomo. D e lo que cabe deducir que no se viven las condiciones de trabajo como alie nadas, determinadas por otros, al margen de cómo sean efectivamente las mismas. En cualquier caso, en aquel momento adoptaba una posición que he mantenido a lo largo de los años: las diferencias entre el trabajo doméstico y el trabajo remunerado no radican en lo que se produce - vida humana, directa 0 indirectamente- , sino en las condiciones de producción.

¿Cómo se llaman los trabajos de las mujeres y de los hombres? ¿Q ué dife rencias hay entre lo que producen las unas y los otros? Ya he mencionado el binomio producción de valores de uso/producción de valores de cambio, así como sus dificultades. En ocasión de las jornadas M ujer y Condiciones de Tra bajo $0^{13}$ empecé a plantearme cuestiones que más adelante desarrollaría en La interdependència de les activitats domèstiquesi el treball remunerat. Estudi com parati u dones/homes ${ }^{14}$. Los binomios trabajo-doméstico/trabajo-remunerado, y valores-de-uso/valores-de-cambio, dejan de lado dos hechos: que buena parte de las mujeres también participa en la esfera mercantil, y que también en esta esfera se produce división sexual del trabajo. Si damos por buena la proposición de que la división sexual del trabajo cruza toda la sociedad, hemos de encontrar el modo de referirnos a ella de un modo consecuente. ¿Tienen algo en común los trabajos de las mujeres, se realicen éstos en la esfera familiar 0 en la mercantil? Si vemos la distribución de las mujeres y de los hombres en las distintas actividades productivas, es incuestionable que la actividad en la que la probabilidad de encontrar mujeres es más al ta es en la de ama de casa, de donde podríamos acabar afirmando que hay un universal y un particular, estando el universal - el resto de las actividades- dominado por los hombres aún cuando participan mujeres y hombres y el particular monopolizado por las mujeres. Sin embargo, en algunas actividades remuneradas la presencia de las mujeres es mayoritaria. ¿Q ué cualidad común tienen estos trabajos? D ecía en aquella ocasión:

[... ] la discriminació de les dones no ha de prendre's únicament com a problema específic de les dones, perquè darrere del problema social de les dones hi ha el símptoma d'un problema que afecta amb la mateixa força les dones que els homes, i és el fet que la divisió sexual del treball, segons la qual les dones produeixen i tenen cura dels éssers humans i els homes produeixen i organitzen el món en què els humans vivim (p. 160).

13. O rganizadas por el Instituto $\mathrm{N}$ acional de Seguridad e H igiene en el Trabajo en 1990. La ponencia quepresenté en las mismas se recoge en «La disponibilidad laboral de las mujeres», Realitat, no 25, 1991.

14. Barcelona, Publicacions del Parlament de Catal unya, 1993. Publicación que recoge los resultados de una investigación que la Comissió d'Estudi per a la I gualtat d'O portunitats $\mathrm{D}$ ona/H ome del Parlament de Catalunya, encargó para conocer la situación de las mujeres en Catalunya. 
[... ] La desvalorització de les dones corre paral lela a la desvalorització de la vida humana. Per més que la desvalorització de les dones pot ser inadmissible per a les dones $\mathrm{i}$ fins $\mathrm{i}$ tot per a les persones amb tarannà democràtic, la desvalorització de la vida humana és un problema d'abast més ampli. És un problema per al conjunt de la població, que requereix mesures de caràcter global, quant a l'organització del treball, a l'estructura de les famílies, al sistema educatiu, en definitiva, a tota l'estructura i les institucions socials (p. 508).

La verdad es que me quedé bastante satisfecha con la anterior conceptualización del trabajo «femenino», y he podido constatar que goza de mucho predicamento, hasta que con ocasión de la organización de unas jornadas ${ }^{15}$, en las reuniones preparatorias de las mismas, S. C ardús y T. C abruja la pusie ron en cuestión, cosa que me dejó bastante perpleja; por suerte, no cayeron en saco roto sus comentarios, los cuales me llevaron a descubrir una inconsistencia en mis planteamientos. Si se toma como punto de partida el proceso de producción del ser humano - producción de sentido de su vida y producción física de su vida y de los medios que la hacen posible - , no tiene lógica afirmar que las unas se dedican a producir la vida humana y los otros a producir la riqueza16. Ya que la única diferencia es si la vida se produce de un modo mediato o inmediato, pero no se produce otra cosa que vida humana. Tanto las actividades productivas ${ }^{17}$ femeninas como las masculinas son relativas a la vida humana.

El trabajo se puede tomar como actividad de producción del ser humano y en el ser humano. En el cuadro se concreta esta actividad en ejemplos que recuerdan sobre todo el trabajo de las amas de casa, sin embargo, es aplicable a todo tipo de trabajo, sea «masculino»0 «femenino». Un cirujano produce ser humano directamente cuando le coloca una prótesis en la cadera, produce en el ser humano la calidad de vida que se deriva de su recuperación funcional.

En última instancia, de lo que se trata no es tanto de producir al ser huma no 0 en el ser humano, sino de producir-se, en el ser humano. La reflexividad del ser humano llevaría en este caso como una condición de necesidad, la rela ción productiva en el otro, a través de la cual realizaría - en el doble sentido de darse cuenta, del término inglés realice y hacer realidad, del término caste

15. Incidencia de género y los val ores en los trabajos de investigación, Instituto Vasco de la M ujer, Vitoria, enero de 1994, cuyas ponencias se recogen en Género y Valores. Vitoria-Gasteiz: Instituto Vasco de la M ujer, 1995. M i aportación fue «Sistema sexo/género y valores: perspectiva materialista».

16. De lo que se podría concluir que las actividades de las mujeres son más importantes que las de los hombres, al aceptar quelos seres humanos son más importantes que sus productos. Ello nos podría conducir a suponer que en condiciones patriarcales tiene lugar un trastrocamiento de la jerarquía de valores, dado que las cosas son más importantes que las personas.

17. Tomo producción en un sentido amplio que incluye las actividades destructivas, las cuales son producción de daño o de destrucción. Por tanto, se trata de un concepto que no contiene connotaciones positivas ni negativas. 
Tabla 1. El trabajo como actividad productiva del ser humano.

\begin{tabular}{lll}
\hline Objeto & De lo que es & De lo que siente \\
\hline $\begin{array}{l}\text { Forma } \\
\text { directa }\end{array}$ & H aciéndole la comida & $\begin{array}{l}\text { Alegrándole con su plato preferido. } \\
\text { M achacádole con algo que no le gusta. }\end{array}$ \\
$\begin{array}{l}\text { Forma } \\
\text { indirecta }\end{array}$ & Cocinando & $\begin{array}{l}\text { Cocinando lo que le gusta para que } \\
\text { se sienta contento. } \\
\text { Cocinando lo que no le gusta para que } \\
\text { sienta fastidio. }\end{array}$ \\
\hline
\end{tabular}

Ilano realizar - quién es. D e tal manera que sea el otro el vehículo de nuestra objetivación como sujetos, al modo como lo expresa M arx en los M anuscritos de economía y filosofía.

Si suponemos al ser humano como ser humano y a su relación con el mundo como una relación humana, sólo se puede cambiar amor por amor, confianza por confianza, etc. Si se quiere gozar del arte, hay que ser un ser humano artísticamente educado; si se quiere ejercer influjo sobre otro ser humano, hay que ser un ser humano que actúe sobre los otros de modo real mente estimulante e incitante. Cada una de las relaciones con el ser humano - y con la naturaleza- ha de ser una exteriorización determinada de la vida individual real que se corresponda con el objeto de la voluntad. Si amas sin despertar amor, esto es, si tu amor, en cuanto amor, no produce amor recíproco, si mediante una exte riorización vital como ser humano amante no te conviertes en ser humano amado, tu amor es impotente, una desgracia18 (p. 181).

Unas relaciones humanas de intercambio consisten en producir-se recíprocamente emociones y sentimientos, el intercambio por excelencia es el del amor como resultado de un acto productivo consciente. Por ello, las relaciones mercantiles no son unas relaciones de intercambio propiamente humanas ${ }^{19}$, ya que al otro se le da aquello que no se quiere para uno mismo como medio de obtener lo que se quiere del otro: un abrigo de visón o una cocina vitroce rámica para despertar amor, que en materia de pal pitaciones cada cual vibra a su modo.

Adicionalmente, si cada una de las relaciones con el ser humano «ha de ser una exteriorización determinada de la vida individual real que se corresponda con el objeto de la voluntad», las relaciones y su exteriorización práctica - los productos de las mismas- han de ser únicas e irrepetibles, aunque se parezcan

18. M anuscritos de economía y filosofía, M adrid, Alianza, 1969. M e he tomado la libertad de substituir el término hombre por ser humano.

19. D ejo aparcada la discusión sobre las implicaciones de presentar el «ser humano» en relación de discontinuidad respecto de los restantes seres vivos, por razones fundamentalmente tácticas. 
las de un día con las del día siguiente y las de una persona con las de otra persona. Los modelos de conducta, las convenciones sociales, que tanto trabajo nos ahorran y tanta certeza nos proporcionan, tienen un coste muy elevado que desconocemos y queremos desconocer: la pérdida de la dimensión activa del sujeto, la reducción del «sujeto» a «objeto sujetado», y la pérdida consiguiente de agencia. La agencia, por otra parte, abre la puerta al abismo de la incertidumbre, por los resultados no buscados de nuestras acciones.

Volvamosal punto en que reconocía mi error y comentaba quela definición del trabajo «femenino» como el de producción de seres humanos ha tenido tan buena acogida. Sobre esta cuestión no se puede pasar por alto, ya que pone de manifiesto la subjetividad de quien investiga y de quien recibe los productos de la investigación. $\mathrm{N}$ o descubro nada nuevo si digo que general mente las personas que trabajamos los temas relativos a la desigualdad social de las muje res somos mujeres nosotras mismas, y nuestra audiencia está compuesta fundamental mente de mujeres. Los hombres no experimentan interés sobre estos temas, a menos que se sitúen en la órbita de la «corrección política». ¿Q uétie nen en común estas tres categorías, entre las que me incluyo, para que acepten como válido el planteamiento al que me vengo refiriendo? En la conceptualización de las actividades de las mujeres objeto de crítica en las páginas precedentes, late un elogio de la diferencia de las mujeres hacia sí mismas 20 que, a mi parecer, apela a una autoridad imaginaria, la cual debe concedernos el derecho a una vida digna.

D e qué modo se justifica que:

- A pesar de reconocerse los hombres excluidos de la producción de la vida humana, no deseen superar la división sexual del trabajo y luchen para superarla, más bien al contrario, se resistan como gato panza arriba a asumir las tareas domésticas de cuidado de la vida humana.

- Es más, ¿cómo se explica que haya mujeres, cada vez más, que se niegan a participar en las actividades de producción de vida humana, porque se han desentendido de los compromisos familiares o porque no los han llegado a adquirir?

- Por añadidura, ipor qué las mujeres que rechazan las actividades productivas femeninas son precisamente las que tienen más poder?

No insistiré sobre los rasgos narcisistas de este discurso. Presentaré, en cambio, otros ejemplos para ilustrar cómo el trabajo investigador, por una parte, y

20. Para ser más precisa, de las mujeres que tienen audiencia cuando reflexionan sobre las mujeres. Se trata de los discursos no sometidos a censura - los censurados los desconocemos-, por lo que tal vez comienza a ser hora de que nos planteemos la importancia de la construcción de discursos de segundo orden, la crítica de la crítica. Por qué ciertos discursos supuestamente críticos sobre la situación social de las mujeres son los hegemónicos. Por qué, a pesar de que en ocasiones están carentes de rigor, apenas se oyen críticas sobre los mismos ni desde el punto de vista teórico ni del político. 
el sentido que algunas mujeres otorgan a sus acciones, por otra, expresan y refuerzan una estructura psíquica, que es propia del orden patriarcal.

\section{H acia una crítica de la crítica: visibilizar el sujeto investigador}

A través de los ejemplos que presento a continuación, me propongo hacer una crítica de la crítica, mostrando que al gunos conceptos pueden ser interpretados como manifestaciones de la dimensión psíquica del orden patriarcal.

En primer lugar, tomaré el concepto doble jornada. La expresión doblejor nada se desarrolló para conceptualizar la situación de las mujeres que se incorporan al trabajo remunerado. Ahora bien, es poco riguroso decir que las mujeres con trabajo remunerado están sometidas a dos jornadas, tal afirmación es contraria a toda evidencia. Al mismo tiempo, es cierto que las mujeres, además de la jornada remunerada tienen una jornada doméstica. N adie es capaz de hacer dobles jornadas, aunque las mujeres adultas con empleo remunerado tienen una jornada laboral más larga que los hombres, si se suman a la jornada remunerada, las horas de trabajo doméstico. En La desigualdad delas mujeres en el uso del tiempo 21 mostré que las mujeres con ocupación remunerada realizan una jornada laboral de 9:30 horas, sumando las actividades domésticas y las remuneradas, mientras que los hombres ocupados declaran un total de 7:45 horas diarias de trabajo. Esta última jornada tienela misma extensión que la que rea lizan las amas de casa. Considerando que otros estudios sobre el uso del tiempo ofrecen resultados parecidos, no cabe afirmar que las mujeres que participan en el mercado de trabajo tengan doble jornada laboral, sino más bien que trabajan 2 horas más que los hombres por término medio. Este hecho ha sido reconocido posteriormente, y ha llevado a que se extendiera el uso de la expresión doble presencia, cuya autoría se atribuye a Laura Balbo. Ya no se pretende afirmar que las mujeres trabajen el doble que los hombres, sino que cuando desempeñan su empleo tienen presentes las responsabilidades domésticas, hemos de deducir que los hombres no, puesto que sobre el particular no se habla.

Cuando esa conceptualización de la situación de las mujeres se contempla a la luz de las diferentes estructuras psíquicas de mujeres y hombres, puede interpretarse ese estar mentalmente en todas partes, no sólo como signo de la desigualdad social de las mujeres, sino que significa también la omnipotencia. Es la otra cara del sentimiento de culpabilidad, ya que una no puede sentirse responsable de aquello que no es capaz de hacer, y una no puede estar en todas partes a la vez. Tanto la expresión doble jornada, como posteriormente doble presencia, que tanto éxito de audiencia han tenido, a la par que hacen visible la desigual dad social de las mujeres, nutren nuestro narcisismo. Pueden ser toma das como indicio de que los discursos de crítica del patriarcado y, por contradictorio que parezca, contienen su afirmación. 
O curre algo similar en la construcción del binomio producción/reproducción. Esta terminología siempre me ha molestado, porque la afirmación de que las mujeres hacen el trabajo llamado reproductivo es como presentar las actividades atribuidas a las amas de casa una función de reproducción social que es aplicable a cual quier actividad que se desarrolle, y no sólo a las que realizan las mujeres. Concretamente, en relación con el capitalismo, el mecanismo fundamental de reproducción social es la valorización del plustrabajo de los trabajadores por parte de los capital istas. En cuanto a la extensión e intensidad de la jornada laboral remunerada, así como la exigencia de disponibilidad de los trabajadores asalariados, es un mecanismo de reproducción del patriarcado, porque favorece y fuerza a la división sexual del trabajo en la casa al hacer incompatible la participación de las actividades asal ariadas con la participación en el trabajo doméstico. En cambio, es más discutible que se puedan considerar la escuela o los medios de comunicación social, como las instituciones cuya función principal sea la «reproducción social», sobre todo si se olvida que fundamental mente son instituciones legitimadoras de que el orden social se reproduzca, cuestión más importante y específica que su función reproductora. D e cualquier modo, el concepto reproducción es anterior al uso de «reproducción» como término aplicado al trabajo que realizan las amas de casa. E s como si en química se hubiera desarrollado el concepto de aleación y a continuación se utilizara para referirse a un proceso químico distinto de aque que previamente se había señalado con un término específico.

Aporta confusión decir que las mujeres son las que se ocupan de la reproducción, y el término tiene resonancias biologistas que no están en la intención de las personas que utilizan esta terminología. Lo que las mujeres hacen no es necesariamente reproducir social o físicamente los seres humanos, porque repro ducción quiere decir 'repetición de lo producido', y las mujeres están sujetas al cambio y también lo generan. Además, el hecho de atribuir la función reproductora a las amas de casa contiene una negación: implica suponer que los hombres no participan en la producción de la vida humana, o que las actividades que realizan los hombres no comportan reproducción física o social. Por el momento, todavía somos una especie sexuada, por lo que los hombres son indispensa bles en la generación de nuevas vidas, y la permanencia de las formas de vida dependen también de las actividades que desarrollan los hombres. Un filete con patatas contribuye a la reproducción de la fuerza física tanto s lo tomamos en un restaurante como si lo cocina nuestra madre, vender la fuerza de trabajo contribuye tanto a la reproducción social como buscar la media naranja para formar una familia. El acto degeneración de la vida humana es un acto procreativo, porque no lo puede realizar una persona sola, y porque lo que se produce mediante la cooperación de dos, es un ser nuevo y diferente. Tal como lo herazonado unas páginas más arriba, la producción de vida humana no es la característica exclusiva del trabajo de las mujeres, lo que nos diferencia son las condiciones de trabajo y la posición que se ocupa en las relaciones de producción.

¿Por qué, entonces, se ha generalizado el uso del binomio producción/repro ducción ? Participar de los argumentos que se han utilizado puede justificar 
la introducción de modificaciones en la conceptualización del trabajo de las mujeres, lo que no queda justificado es la terminología que se emplea para referirse a esa conceptualización. Se me ocurren dos factores que han intervenido en que esto suceda. En primer lugar, el hecho de que no haya sido sometido a revisión crítica el uso del término reproducción en un sentido distinto al que se le atribuye en el ámbito de las ciencias sociales, puede indicar que la «sociología del género», al ganar un espacio propio, ha quedado aislada, por lo que se acepta que los términos y conceptos que se utilizan en la misma tengan un encaje teórico muy distinto del que tiene en las ciencias sociales tomadas en su conjunto - cosa que requiere una justificación que no se ha dado. El aislamiento en que se encuentra la «sociología del género» permite pasar de puntillas sobre estas contradicciones, sin argumentar por qué se producen o bien sin cuestionar a las ciencias sociales el desarrollo del concepto reproducción en el seno de estas disciplinas, cosa que no se ha hecho. En segundo lugar, creo que también éste es un indicio del peso de la estructuración psíquica sobre el proceso de producción de conocimiento, similar al que señalaba cuando revisaba el error de suponer que son las mujeres las que producen la vida humana, tomando a una parte, las mujeres, por el todo, y siendo el todo para los seres humanos, los propios seres humanos.

0 tro indicio de los efectos de la estructura psíquica patriarcal sobre el discurso crítico del patriarcado es afirmar la necesidad de valoración del trabajo doméstico realizado por las amas de casa. 0 el trabajo teórico y práctico sobre la autoestima de las mujeres. Las palabras hablan por sí mismas, más allá de lo que se pretende decir conscientemente. No se habla de «evaluación», sino de «valoración» o visibilización del trabajo de las mujeres. Valo ración indica virtualmente que se confunde lo positivo con lo normativo, y visualización que se quisiere situar el trabajo de las mujeres bajo el foco de la mirada. ¿N o es acaso una forma social de expresar la demanda «Pepe, no me has dicho si estoy guapa. ¿M e quieres?»? C omo si una tuviera que merecer la vida, o como si su continuidad y calidad dependiera de un ser superior imaginario - a lo peor El Patriarca- , porque si una sitúa esas demandas con relación a un ser real, es posible que opte por ejercer el control sobre su vida, en lugar de buscar el reconocimiento y apoyo de aquél al que se le confiere autoridad.

No es el momento para extenderme sobre la cuestión del valor, me limitaré a apuntar que los valores se construyen socialmente, y si se exige, o se pretende que es posible la valoración del trabajo doméstico, mepregunto si no se estará proponiendo que sea el resultado de una determinación social y no individual. D eterminar el val or de las paellas que cocinamos en casa es tanto como determinar cómo se lo ha de montar una o uno para hacer sus paellas, y por ello contiene sobre todo un elemento normativo. D e lo contrario, cada cual asignaría a sus paellas el valor que le resultara oportuno, en el sentido de dedicarle el tiempo y los recursos que corresponde a la importancia que se les da, las paellas serían una expresión de la subjetividad y por ello no existiría el uni- 
versal PAELLA objeto de valor universal, «objetivo»æ2. Lo que se presenta como un instrumento de liberación contiene mecanismo de control social, vigilancia, obediencia, porque al valorar las paellas se les dice a las mujeres implícitamente el tiempo que deben dedicar y la propia conveniencia de cocinarlas. Convendría tener un poco más en cuenta lo que dice Foucault sobre el paso del uso del castigo al de la vigilancia, como mecanismo de control social.

Además, conviene no olvidar el papel de las O N G en la propuesta de visibilizar el trabajo no pagado, mediante la creación de una cuenta satélite que contemple todos los trabajos no pagados, y no sólo los de las amas de casa. Esa valoración económica facilitaría negociar las subvenciones y pervertir el sentido del trabajo de voluntariado, que gradual mente se está traduciendo en una privatización de los servicios públicos, y una pérdida del valor expresivo de este tipo de actividades. ¿Cuál es nuestro móvil político: que no haya amas de casa como actividad de un colectivo específico, porque todas y todos lo seamos, o caer en la afirmación producto del narcisismo constitutivo de la identidad femenina diciendo: «iM ecachis que guapas son!», y olvidando las implicaciones psíquicas de esta demanda de reconocimiento, con todo lo que contiene de subordinación?

Por uno u otro camino se desarrollan discursos que confluyen en dos puntos. En parte se centran en la crítica de la desigualdad social de las mujeres, otra parte, en el elogio de la diferencia femenina. Respecto de la crítica a la desigualdad, progresivamente se han ido obscureciendo los aspectos estructurales de la misma, lo que ha conducido a discursos que exigen la culminación de la revolución liberal, extendiendo la demanda de igualdad de derechosindi viduales a la igual dad de resultados individuales. Pero, en cualquiera de los dos casos, se construye una noción de ser humano igual a individuo, y la noción de derechos, libertadesy oportunidades del individuo. Como si fuera posible que las mujeres pudieran tener lo que tienen los hombres, cuando es precisamente la desigualdad social la que construye las categorías «mujer»y «hombre», junto con sus atributosy posesiones mutuamente excluyentes. Porque la «mujer» y el «hombre» son efectos del orden, por más que los discursos sobre la desigualdad social de las mujeres, en la academia y fuera de ella, toman a las unas y a los otros como anteriores a la desigualdad. Se produce lo contrario de lo que aparentemente se propugna, la reificación de la desigualdad, y la constitución de un cuerpo de profesionales especializados que patrullan socialmente poniendo orden.

D e forma parecida, se insiste en los valores positivos de las mujeres y se denuncia la marginación social de lo femenino por considerarla una mutilación. La paradoja es que se argumenta la inexistencia de una separación entre la esfera pública/ política y la privada/ personal - lo personal es político- , para a continuación afirmarla, al suponer que lo femenino está ausente de lo público, en lugar de analizar la presencia de lo femenino en la esfera pública como un modo de expresión del patriarcado, y no como su crítica. La recuperación

\section{Creo que es evidente que me encantan las paellas.}


de lo materno hecha desde el discurso crítico, por tomar un ejemplo, es asombrosamente parecido a la concepción dominante de las supuestas cualidades maternas, las cuales tienen un espacio público, y lo que es peor, en ambos casos se produce una reificación de «la madre» y «a maternidad». ¿C abe hablar de dife rencias allí donde hay explotación y dominación, allí donde hay desigualdad? ¿C abe afirmar que las mujeres están sometidas, cosificadas y sin embargo no estén dañadas intelectual y moralmente? Si un sistema de explotación y dominación nos hace maravillosas, no veo qué interés tiene cambiarlo, sobre todo cuando en ese tipo de discursos reivindicativos y reificadores de las cualidades femeninas, contienen una afirmación del ser frente al poseer ${ }^{23}$, como el patriarcado nos quita cosas pero nos da esas cualidades personales supuestamente positivas, ¿cuál es el problema?, lo uno compensa ampliamente lo otro.

\section{La ética de la similitud24}

Recapitulando las características que atribuyo a mi trabajo, se podría resumir del siguiente modo:

1. A lo largo del tiempo he mantenido el criterio de aplicar, en la medida de lo posible, una óptica transdisciplinaria, buscando la relación entre la estructura social y la estructura psíquica.

2. M e he decantado gradualmente hacia proyectos que no requirieran financiamiento, por las servidumbres que los mismos comportan.

3. He buscado establecer una línea de continuidad entre la docencia y la inves tigación, no sólo porque el trabajo de investigación se refleje en la docencia, sino también porque la investigación contenga ella misma un componente docente.

Esta posición frente a la investigación se ilustra con trabajos ya mencionados, como Aguantando el tipo, en el cual se materializan las lecturas y los deba

23. Esa afirmación contiene nuevamente un cierto rasgo de narcisismo primitivo.

24. Situaría en esta postura trabajos como «Los órdenes de la violencia: especie, sexo y género» en V. FISAS (ed.). El sexo de la violencia: La fascinación masculina por la violencia, Barcelona, I caria, 1998, en que se recogen las jornadas con el mismo titulo celebradas en la Facultat de Ciències Polítiques i Sociologia en noviembre del año 1997. El malestar en la desigualdad. M adrid: Cátedra, 1998. «El vínculo social: una lectura sociológica de Freud. Papers, revis ta de sociol ogia. 1996. «C onstrucción de la subjetividad: estructura social y escuela». Lleida: Institut de Ciències de l'Educació, 1997. GESES. «Entre risas, lágrimas y golpes. De la agresión a la demanda de amor en los chistes sobrehombres y mujeres», El Viejo Topo oㅡ 113, diciembre 1997. GESES Grupo de Estudio: Sentimientos, Em ocion es y SOCIEDAd. «D e la agresión a la demanda de amor en los chistes sobre hombres y mujeres». D ebate Feminista, vol. 17, 1998, (participaron en la elaboración de estos artícul os: Ana Alcantud, N atalia C antó, I ngrid Llopart, Laura M encía, Laia Pineda, y Laura Torrebadella), «Relacions socials i patiment humà», en José LEAL, M aría Jesús IzQuierdo y Jordi GaRRETA. El malestar social y la educación», Lleida, Institut de Ciències de l'Educació, 1998. 
tes de muchos años de seminario con un grupo de ex-alumnas y alumnos y actuales profesores. Un segundo proyecto de este tipo es el G rupo de Estudios Sentimientos Emociones y Sociedad (GESES).

En este segundo proyecto se recoge, además, la creciente tensión que he experimentado con el uso de las técnicas de trabajo de campo: entrevista con preguntas cerradas, entrevista estructurada y entrevista en profundidad. En ellas percibo la existencia de un elemento de violencia, de poder, de censura, de vigilancia que me hace sentir mal. El proyecto, que de una manera lenta, pero continua, vamos desarrollando, se podría situar en el ámbito de la investigación acción, buscando las relaciones entre la dimensión estructural psíquica y la social, y llevando al terreno de lo social al gunas aportaciones del método, la técnica y la teoría psicoanalíticas. M ueve a realizar este trabajo el afán de conocer, por supuesto, pero más que cualquier cosa el sufrimiento humano evitable. Algo parecido a la propuesta de Rorty consistente en describir el sufrimiento en todas sus formas, porque el reconocimiento de similitud en el sufrir puede ser una base muy sólida para construir solidaridad sin que se ahoguela aspiración a la libertad. Ahora bien, Rorty considera que ésta es una tarea de descripción que confía a la narración literaria. N uestra ambición, en cambio, es desarrollar un trabajo socioanalítico de aquellas elaboraciones mediante las cuales el suje to hace invisible su sufrimiento.

¿Cómo se realiza trabajo empírico pidiéndole a la gente que haga algo que le gusta hacer, en lo que no se sienta violentada y que por sí mismo genere bienestar? D esarrollar una línea de trabajo sobre el análisis de los chistes y la relación entre los chistes que la gente cuenta y su posición social, es una respuesta a esta aspiración. Así como generalmente hay un cierto rechazo a ser observado o inte rrogado, en el caso de los chistes la gente nos los quiere contar, nos para con el fin de contárnoslos, quieren que los conozcamos. Esta línea de trabajo nace del efecto que hace aproximadamente cuatro años me causó el siguiente chiste:

- D olores, tengo que darte un disgusto muy grande, tu marido te engaña.

- ¡Q ué vergüenza, con lo mal que lo hace!

La primera impresión fue que presentaba una imagen positiva de las mujeres, ya que aparentan ser invulnerables respecto del daño que les puedan causar los hombres. Luego comprendí que, en realidad, en el chiste aparecían las huellas psíquicas que el patriarcado deja en las mujeres: D olores vive con un hombre que hace mal el amor, el agente supuestamente es él, ya que ella se asigna un papel pasivo en la relación. Al mismo tiempo, D olores vive a su marido como una extensión de sí misma, como su vicario en la esfera pública, ya que experimenta vergüenza por sus actuaciones. El chiste manifesta un imaginario en que la mujer queda dibujada como agente que no actúa directamente, sino que requiere de la mediación del otro, el cual es su instrumento. Éste y al gunos otros chistes los anal izamos en la asignatura de Sociología de la Familia, y al acabar el curso les propuse a algunas al umnas y alumnos que continuáramos trabajando el tema, y en eso estamos. 
Sin pretenderlo, en los primeros trabajos realizados nos hemos encontrado con algo que no buscábamos, el sufrimiento de los hombres, los daños emocionales que les causa el patriarcado, ese sentirse instrumentalizados, no ser deseados por ellos mismos, sino por las cosas que pueden proporcionar a las mujeres. Anticipábamos que encontraríamos mucha violencia, cosa que se ha confirmado. Pero el análisis de los chistes ha puesto de manifiesto algo que no esperábamos encontrar, la queja de los hombres, y ésta, en la medida en que se expresa en forma de chiste, es indicio de la sordera de las mujeres. En estos momentos nos preguntamos cuánto dolor contiene la violencia de los hombres.

I lustraré lo que acabo de afirmar sobre los daños emocionales del patriarcado con algunos ejemplos:

- ¿En qué momento gritan las mujeres al hacer el amor?

- Al acabar, cuando te la limpias en las cortinas.

Lo obvio es la agresión hacia una mujer cuando ensucia las cortinas, pero es que ella, hasta entonces, no había emitido ningún grito. ¿N o es acaso una queja del hombre, que tomando a la mujer como objeto de deseo, desea que ella sea sujeto deseante, no una cosa, y que sólo se expresa como sujeto con relación a las cosas, las cortinas?

- ¿Q ué es mejor, un polvo o una buena cagada?

- La cagada, porque al acabar no te tienes que pasar un cuarto de hora abrazando la taza.

Aquí se manifesta el rechazo del hombre a la necesidad de la mujer de que la quieran. Se podría suponer que la quiere como mero instrumento de placer, y cabe también interpretar, según la resonancia emocional que genere el chiste, que no es agradable practicar el sexo con alguien que no lo disfruta en sí mismo, y tal vez lo utiliza como medio para recibir atención.

- ¿Cuál es el colmo del matrimonio?

- Q ue casándote para tener un jaguar en el garaje, un visón en el armario y un tigre en la cama, acabas teniendo un panda en el garaje, un conejo en el armario y un cerdo en la cama.

En este caso es tan evidente la instrumentalización del hombre por parte de la mujer que no requiere comentarios.

- Pero animal, ¿por qué pegas a tu mujer?

- No lo sé. Pero ella sí que lo sabe.

Si es ella quien sabe por qué hace las cosas, quiere decir que en él no hay intenciones y en ella sí, de lo contrario, la pregunta sería para qué pegas a tu mujer. En otras palabras, en este chiste se recoge al go que apuntábamos unas 
páginas más arriba, que las mujeres desarrollan una «pasividad activa» consistente en manipular a los demás para que hagan las cosas.

Un indicio de que los procesos de cambio no son vividos como obra del destino, es que el discurso sobre los mismos está acompañado de una prome sa de felicidad. Eso es lo que encontramos el siglo XVIII, en la proliferación de tratados sobre el arte del bien vivir y la felicidad. Porque, tal como lo señala Freud en El malestar en la cultura, lo que los seres humanos expresan a través de su conducta es que quieren ser felices y, cuando lo consiguen, no quieren dejar de serlo. Si la felicidad no es posible, persiguen al menos no sufrir. Ése es $\mathrm{l}$ afán que este autor detecta tras producciones como la ética y la justicia. La ética da cuenta de esa parte nuestra que reconoce su necesidad de los demás para ser feliz, la cual nos conduce a los deseos y los amores de segundo orden, desear aquello deseable y desear ser amados por aquellas cualidades que definimos como susceptibles de merecer amor. Junto a la demanda y promesa de amor, anida en nosotros el deseo de destruir todo obstáculo a nuestra felicidad, de instrumentalizar a los otros, de utilizarl os contra su voluntad y deseo. D e esa parte nuestra nace la exigencia de justicia, entendida ésta como la fuerza de una inmensa mayoría de débiles que se otorgan la ley, contra los poderosos y sus deseos arbitrarios por una parte, y contra la realización de aquellos dese os propios que nos llevan a oponernos a nuestros compañeros por similares en la fragilidad y la capacidad de experimentar sufrimiento. La unión de los débiles no cabe relacionarla únicamente con la dimensión de la ética de nuestras vidas, sino que más bien da cuenta de la dimensión política. La ausencia de ley, tal como la entiendo, hace temer que la rabia y la ira que experimentamos cada vez que se frustran nuestros deseos ronde las calles, causando sufrimiento a otros bajo el influjo de la envidia, sin que nos aporten felicidad. El rechazo de la ley que los débiles se dan a sí mismos surge cuando no somos capaces de reconocer nuestra debilidad, en el mismo grado en que continuemos confiando que un ser imaginario todopoderoso, ese patriarca que suplantó al padre, nos saque las castañas del fuego. Esa resistencia a crecer se expresa incluso en el trabajo de investigación, el cual está trufado de esa sintomatología, porque preten demos aportar el punto de vista de las mujeres sin haber elaborado pre viamente cómo se ha construido en cada una de nosotras ese punto de vista, sin entender que las «mujeres» y los «hombres» son efecto de relaciones patriarcales, síntomas de la pervivencia de este tipo de relaciones. Eso es lo que tene mos en común, el daño y el sufrimiento, no siempre expresado conscientemente, que padecemos y a la vez contribuimos a causar, y que aceptamos a cambio de conservar el ideal de omnipotencia que se escapa en muchos de nuestros discursos, tanto sobre la desigualdad social de las mujeres como sobre la diferencia. Éste es el tipo de discursos que goza de más audiencia. Se trata de los discursos no sometidos a censura - los censurados los desconocemos- , por lo que tal vez comienza a ser hora de que nos planteemos cómo es de importante la construcción de discursos de segundo orden, la crítica de la crítica, lo que nos permitirá resolver algunos interrogantes: ¿Por qué ciertos discursos supuestamente críticos sobre la situación social de las mujeres son los hegemónicos? 
¿Por qué a pesar de que en ocasiones están carentes de rigor, apenas se oyen críticas sobre los mismos ni desde el punto de vista teórico ni del político? ¿Por qué si tenemos las ideas tan claras los discursos que construimos llegan a tan poca gente? ¿Por qué si la situación de las mujeres es un problema de género y de relaciones entre los géneros y no de sexo, la sociología del género vive en un aislamiento voluntario? cado.

$\mathrm{N}$ uestro trabajo no llega a ser crítico, pero todavía es un síntoma del patriar- 